American Journal of Animal and Veterinary Sciences 7 (1): 1-6, 2012

ISSN 1557-4555

(C) 2012 Science Publications

\title{
Early Age Thermal Conditioning Improves Broiler Chick's Response to Acute Heat Stress at Marketing Age
}

\author{
${ }^{1}$ Ahmed M. Hassan and ${ }^{2}$ P. Gopal Reddy \\ ${ }^{1}$ Department of Animal Hygiene, Zonosses and Animal Behavior, \\ Faculty of Veterinary Medicine, Suez Canal University, Ismailia, Egypt \\ ${ }^{2}$ Department of Pathobiology, College of Veterinary Medicine, \\ Nursing and Allied Health, Tuskegee University, Al 36088, Tuskegee
}

\begin{abstract}
Problem statement: Acute heat stress at marketing age especially in broiler chickens raised in open houses with reduced means of heat exchange leads to economic losses. The objective of this study was to determine beneficial effects of early age thermal conditioning in reducing adverse effects of acute heat stress and decrease losses. Approach: Ninety one day-old broiler chicks were randomly assigned to one of three treatments $(n=30)$ : (1) control (normally raised), (2) early age thermal conditioning (exposed to temperature of $40 \pm 1^{\circ} \mathrm{C}$ for $24 \mathrm{~h}$ at 5 th day of age, then raised as control chicks) and (3) chronic stress (exposed to $33 \pm 2{ }^{\circ} \mathrm{C}$ from day one till 6 weeks of age). At 42 nd day of age, all chicks were subjected to acute heat stress of $39 \pm 2^{\circ} \mathrm{C}$ for $2 \mathrm{~h}$. Blood samples were collected from all groups before and after exposure to acute heat stress. Results: Blood $\mathrm{pH}$ increased in both controls and thermally-conditioned chicks after exposure to acute heat stress coinciding with significant decrease in blood carbon dioxide pressure $\left(\mathrm{pCo}_{2}\right)$ in controls only. Blood potassium level decreased in controls, while in thermally-conditioned or chronically-stressed no significant changes were observed. Blood sodium level showed a trend toward decreased levels in controls while a trend toward increased levels was observed in both thermally-conditioned and chronically-stressed birds. Importantly, significant reductions were observed in total erythrocyte count and hemoglobin level in chronically-stressed birds as compared to other groups before and after acute stress exposure. Hetrophil/lymphocyte ratio increased in both controls and thermally-conditioned chicks after acute heat exposure, but not in chronically-stressed birds. Conclusion: When exposed to acute heat stress at marketing age, chicks subjected to early age thermal conditioning responded very similar to birds adapted to chronic heat stress indicating a protective role of early age thermal conditioning.
\end{abstract}

Key words: Heat stress, early age thermal conditioning, blood gases, blood electrolytes

\section{INTRODUCTION}

Poultry production in tropical countries is affected by many challenges especially during the hot humid summer season. Economic losses result from decreased productivity and increased mortality due to acute heat stress. Among many factors, chick's age plays an important role in its resistance to acute heat stress. Heat loss from the surface of chicken to the environment increases from day one till four weeks of age and then decrease during the last two weeks of the growth period of broiler chicken (Cangar et al., 2008). Heavier broilers (approaching marketing age) are sensitive to high-temperature challenges. This sensitivity can be explained by the fact that broilers have greater difficulty keeping thermal homeostasis due to the large body mass and high rate of metabolism associated with rapid growth (Borges et al., 2003). Low ability of heat loss of broiler chicks during the last two-weeks increases the impact and risk of exposure to elevated environmental temperature.

Panting by poultry allows them to increase their evaporative heat loss during heat stress. This increased respiratory rate causes changes in the gas exchange and acid-base balance in the broilers which is due to loss of carbon dioxide from the respiratory system. The effect of these reactions is a high level of blood $\mathrm{pH}$. There is also relative loss of bicarbonate and hydrogen ions which creates a situation of respiratory alkalosis during heat exposure (Borges et al., 2004). Potassium level

Corresponding Author: Ahmed M. Hassan, Department of Animal Hygiene, Zonosses and Animal Behavior, Faculty of Veterinary Medicine, Suez Canal University, Ismailia, Egypt Tel: 334-724-4438 Fax: 334-724-4488 
reduction in heat-stressed birds increases intracellular accumulation of basic amino acids including glutamic acid, which has been proposed to play an important role in metabolic regulation of acid-base balance (Austic and Calvest, 1981).

Heat exposure for $24 \mathrm{~h}$ at 5 days of age described as early age Thermal Conditioning (TC) has been proposed as a technique to reinforce resistance of broiler chickens to acute heat stress during the finishing period (Yahav and Hurwitz, 1996; Zhou et al., 1997; Arjona et al., 1988; Yahav and Plavnik, 1999). Exposure to heat stress in poultry can be described as acute heat stress that refers to a short and sudden period of extremely high temperatures, whereas chronic heat stress refers to extended periods of elevated temperatures. There is lack of information on the mechanisms involved in response to acute heat stress at marketing age with respect to broilers raised under conditions of chronic heat-stress or thermallyconditioned at an early age. Therefore the main objective of this study was to evaluate changes in some important blood parameters of broilers subjected to early age thermal conditioning as compared to control non- stressed or chronically stressed broilers when all the three groups were subjected to acute heat stress at marketing age.

\section{MATERIALS AND METHODS}

Experimental chicks: A total of ninety one-day old Hubbard chicks were assigned randomly to one of three treatment groups $(\mathrm{n}=30)$. Control group was raised under normal conditions without exposure to any heat stress. The second group was subjected to chronic heat stress from day one through 42 days of age by exposure to environmental temperature of $33 \pm 2{ }^{\circ} \mathrm{C}$ (Abu-Dieyeh, 2006). The third group was treated similar to control group except that the birds were thermally-conditioned at 5 th day of age by exposure to elevated temperature of $40 \pm 1^{\circ} \mathrm{C}$ for $24 \mathrm{~h}$ (Basilio et al., 2001). All chicks were reared on deep litter at a stocking density of $10 \mathrm{birds} / \mathrm{m}^{2}$ and kept under $23 \mathrm{~h}$ light $-1 \mathrm{~h}$ darkness. Feed and water were provided ad libitum.

Exposure to acute heat stress: Chicks were kept in controlled environmental chamber with dimensions of $1.80 \times 2.40 \times 2.34 \mathrm{~m}$. Chamber was provided with thermostatically-controlled electric heater and small electric fan for the circulation of the air, two holes of 16 $\mathrm{cm}$ diameter were made to provide ventilation. At $42 \mathrm{nd}$ day of age all chicks were subjected to acute heat stress of $39 \pm 2^{\circ} \mathrm{C}$ for $2 \mathrm{~h}$ (Altan et al., 2000). With this acute heat exposure birds showed typical heat stress responses. These included increased water consumption, chicks moving away from other birds, lifting the litter to find a cool surface, lifting their wings, resting to reduce energy and panting.

Sample collection and testing: At 42nd day of age before and after exposure to acute heat stress, 10 birds were randomly picked up from each group. Blood samples were collected from the wing vein directly into a heparinized $(50 \mathrm{IU} / \mathrm{mL})$ syringe. All bleedings were completed within $45 \mathrm{~s}$ after the birds were caught. Blood samples were kept in ice bags and immediately transferred to the laboratory. Blood sample was drawn directly from the syringes into a blood gas/electrolyte analyzer (Genn Premier 3000, Instrumentation laboratory, Lexington, MA, USA) for immediate analysis of partial pressure of $\mathrm{CO}_{2}\left(\mathrm{pCO}_{2}\right)$, partial pressure of $\mathrm{O}_{2}\left(\mathrm{pO}_{2}\right), \mathrm{pH}$, hematocrit (Hct) and electrolytes $\left(\mathrm{Na}^{+}, \mathrm{K}^{+}, \mathrm{Ca}^{2}\right)$.

Heterophil/Lymphocyte (H/L) ratio was determined according to Gross and Siegel (1983). Total erythrocytic count (RBC count) was performed and Hemoglobin $(\mathrm{Hb})$ concentration was measured calorimetrically, using a diagnostic kit according to the manufacturer instructions.

Statistical analysis: Results are expressed as means \pm SEM for each group. Groups were tested for differences by performing the ANOVA and fisher's least protected significance test using the Statview 4.53 software (Abacus Concepts Inc., Berkeley, CA). Differences were considered statistically significant at $\mathrm{p}<0.05$.

\section{RESULTS}

Blood $\mathrm{pH}$ and gases (Table 1) indicated that heat stress at marketing age led to significantly increased blood $\mathrm{pH}$ of control and thermally-conditioned chicks as compared to before acute stress, while chronically stressed chicks did not reveal significantly elevated $\mathrm{pH}$ values although there was a trend toward increased values. Blood $\mathrm{Co}_{2}$ level showed marked significant differences. In control chicks, there was a significant reduction in its level after exposure to acute heat stress. On the other hand, thermally-conditioned and chronically-stressed chicks showed only a little non significant decrease in Blood $\mathrm{Co}_{2}$ level as compared to levels before exposure to acute stress. 
American J. Animal \& Vet. Sci., 7 (1): 1-6, 2012

Table 1: Blood $\mathrm{pH}$ and gases concentration of broilers in response to acute heat stress at marketing age

\begin{tabular}{lllll}
\hline Treatment & \multicolumn{2}{c}{$\mathrm{PH}$} & $\mathrm{pCO}_{2}(\mathrm{~mm} \mathrm{Hg})$ & $\mathrm{pO}_{2}$ \\
\hline Control & Before & $7.30 \pm 0.03^{\mathrm{c}}$ & $60.27 \pm 6.04^{\mathrm{a}}$ & $52.43 \pm 3.22^{\mathrm{a}}$ \\
& After & $7.40 \pm 0.02^{\mathrm{b}}$ & $45.23 \pm 2.71^{\mathrm{b}}$ & $50.70 \pm 6.26^{\mathrm{a}}$ \\
Thermally- & Before & $7.36 \pm 0.04^{\mathrm{c}}$ & $45.23 \pm 2.71^{\mathrm{b}}$ & $52.43 \pm 3.22^{\mathrm{a}}$ \\
Conditioned & After & $7.45 \pm 0.20^{\mathrm{ab}}$ & $41.47 \pm 0.97^{\mathrm{b}}$ & $48.97 \pm 3.03^{\mathrm{a}}$ \\
Chronically- & Before & $7.42 \pm 0.02^{\mathrm{ab}}$ & $42.70 \pm 1.99^{\mathrm{b}}$ & $52.07 \pm 1.36^{\mathrm{a}}$ \\
stressed & After & $7.50 \pm 0.03^{\mathrm{a}}$ & $41.37 \pm 3.29^{\mathrm{b}}$ & $49.67 \pm 2.67^{\mathrm{a}}$ \\
\hline *: Treatment means & with different & superscripts & are & significantly \\
different $(\mathrm{p}<0.05)$ & & &
\end{tabular}

Table 2: Blood electrolyte concentration of broilers in response to acute heat stress at marketing age

\begin{tabular}{lllll}
\hline Treatment & & Calcium & Potassium & Sodium \\
\hline Control & Before & $1.89 \pm 0.12^{\mathrm{a}}$ & $5.65 \pm 0.19^{\mathrm{a}}$ & $135.30 \pm 6.7^{\mathrm{a}}$ \\
& After & $1.94 \pm 0.16^{\mathrm{a}}$ & $5.11 \pm 0.25^{\mathrm{b}}$ & $133.97 \pm 2.72^{\mathrm{a}}$ \\
Thermally- & Before & $1.95 \pm 0.16^{\mathrm{a}}$ & $5.20 \pm 0.05^{\mathrm{b}}$ & $133.97 \pm 2.72^{\mathrm{a}}$ \\
conditioned & After & $1.78 \pm 0.04^{\mathrm{a}}$ & $5.20 \pm 0.05^{\mathrm{b}}$ & $136.80 \pm 1.474^{\mathrm{a}}$ \\
Chronically- & Before & $1.79 \pm 0.12^{\mathrm{a}}$ & $5.48 \pm 0.14^{\mathrm{b}}$ & $134.57 \pm 2.46^{\mathrm{a}}$ \\
stressed & After & $1.87 \pm 0.06^{\mathrm{a}}$ & $5.27 \pm 0.06^{\mathrm{b}}$ & $135.67 \pm 1.67^{\mathrm{a}}$ \\
\hline *: Treatment means & with different & superscripts & are significantly \\
different $(\mathrm{p}<0.05)$ & & &
\end{tabular}

Table 3: Blood parameters in response to acute heat stress of broilers at marketing age

\begin{tabular}{llllll}
\hline Treatment & & RBCs count & $\mathrm{Hb}(\mathrm{g} / \mathrm{dL})$ & $\mathrm{Hct}(\%)$ & $\mathrm{H} / \mathrm{L}$ ratio \\
\hline Control & Before & $3.77 \pm 0.65^{\mathrm{ab}}$ & $11.10 \pm 0.37^{\mathrm{a}}$ & $28.33 \pm 0.33^{\mathrm{b}}$ & $0.19 \pm 0.03^{\mathrm{b}}$ \\
& After & $3.73 \pm 0.48^{\mathrm{ab}}$ & $10.56 \pm 0.44^{\mathrm{a}}$ & $32.33 \pm 0.89^{\mathrm{a}}$ & $0.40 \pm 0.02^{\mathrm{a}}$ \\
Thermally- & Before & $4.45 \pm 0.31^{\mathrm{a}}$ & $11.57 \pm 0.17^{\mathrm{a}}$ & $34.00 \pm 0.33^{\mathrm{a}}$ & $0.21 \pm 0.02^{\mathrm{b}}$ \\
conditioned & After & $4.37 \pm 0.30^{\mathrm{a}}$ & $10.62 \pm 0.33^{\mathrm{a}}$ & $32.33 \pm 1.53^{\mathrm{a}}$ & $0.39 \pm 0.05^{\mathrm{a}}$ \\
Chronically- & Before & $2.96 \pm 0.32^{\mathrm{b}}$ & $8.86 \pm 0.57 \mathrm{~b}$ & $24.33 \pm 2.03^{\mathrm{b}}$ & $0.38 \pm 0.05^{\mathrm{a}}$ \\
stressed & After & $2.95 \pm 0.36^{\mathrm{b}}$ & $8.39 \pm 0.21^{\mathrm{b}}$ & $23.00 \pm 2.09^{\mathrm{b}}$ & $0.42 \pm 0.02^{\mathrm{a}}$ \\
\hline
\end{tabular}

*Treatment means with different superscripts are significantly different $(\mathrm{p}<0.05)$

No differences were found in any of the treated groups in blood $\mathrm{O}_{2}$ levels; however there was a trend toward decreased levels due to stress.

Data in Table 2 indicates that there were different patterns in electrolyte levels in different groups. Acute heat stress at marketing age revealed no significant effect on both calcium and sodium levels in all the three groups. However, potassium level was significantly lower only in the control group after exposure to acute heat stress.

Hematological data (Table 3) revealed that chicks exposed to chronic heat stress had significantly $(\mathrm{p}<0.05)$ decreased number of circulating RBCs, Hb concentration and Hct \% as compared to both controls and thermally-conditioned chicks. Hct showed a different pattern as there was a significantly increased level in control chicks after exposure to acute heat stress while there was decrease in thermallyconditioned and chronically-stressed chicks as compared to before acute stress levels. Our results (Table 3) indicated that $\mathrm{H} / \mathrm{L}$ ratio significantly increased in both controls and thermally-conditioned chicks after acute heat stress as compared to before exposure to heat stress. However, in chronicallystressed chicks there was no significant difference but only a trend toward increasing ratio as a result of acute heat stress.

\section{DISCUSSION}

With reference to changes in blood $\mathrm{pH}$ and blood gases, it was clear that chronically-stressed chicks revealed no significant changes following acute heat stress at marketing age. This might be attributed to adaptation of these chicks as continued exposure of the birds to high temperature promotes adaptive responses (Borges et al., 2003). Blood $\mathrm{Co}_{2}$ levels showed significant differences between groups. In control chicks, there was a significant reduction in its level. Exposure to acute heat stress in control chicks caused an increase in respiratory rate (panting) and resulted in reduction in blood $\mathrm{pCo}_{2}$. This finding is in agreement with that reported by Raup and Bottje (1990); Macari et al. (2002) and Borges et al. (2004). On the other hand, thermally-conditioned chicks behaved like the chronically-stressed reflecting the importance of chick conditioning at an early age to adapt the waves of stress at marketing age. No differences were found in any of the treated groups in blood $\mathrm{O}_{2}$ levels; however there was a trend toward decreased level due to stress.

Electrolytes and water balances in the body are maintained within strict limits and under thermoneutrality birds theoretically have an optimal internal electrolyte balance. Sodium and potassium levels are essential for synthesis of tissue proteins, maintenance of intracellular and extra cellular homeostasis, electrical potential of cell membranes, enzymatic reactions, osmotic pressure and acid-base balance (Borges et al., 2003). Decreased potassium level in serum of control group after exposure to acute heat stress might be due to shift between muscle and extra cellular fluid, increased renal excretion, increase in potassium ions uptake of erythrocytes and/or skin (Smith and Teeter, 1987; Ait-Boulahsen et al., 1989). Our finding agrees with that of Cheveille (1979) who reported depressed blood potassium level in heat stressed poultry. Similar to the results observed in the case of blood gases, electrolyte level responses of thermally-conditioned chicks were similar to chronically-stressed chicks which are adapted to heat stress. Blood calcium increased in controls after acute heat stress but decreased in both thermally-conditioned and chronically-stressed chicks. Ching et al. (1992) also reported increased blood calcium levels in broilers subjected to heat stress. Blood sodium showed a different pattern, it was decreased in controls after acute 
heat stress but was slightly increased in both thermallyconditioned and chronically-stressed chicks. Previous studies have shown that blood sodium level is affected by heat stress. Results of this study showing reduced $\mathrm{Na}^{+}$level in controls after acute heat stress is in accordance with those reported by Deyhim et al. (1990) and Belay and Teeter (1993). This could be attributed mainly to hemo-dilution which causes a lowering of $\mathrm{Na}$ concentration. Wideman et al. (1994) concluded that acute heat acclimated broilers exposed to $35^{\circ} \mathrm{C}$ had significantly lower Glomerular Filtration Rate (GFR), filtered load of sodium and tubular sodium reabsorption rates than the control birds. These changes in kidney function are considered to play a role in minimizing urinary fluid and solute loss when heat acclimated broilers consume large quantities of water to support evaporative cooling.

Generally, during acute heat stress in poultry, variable changes in urinary electrolyte excretion have been reported. The study of Belay and Teeter (1993) showed that exposing chicks to acute heat stress $\left(35^{\circ} \mathrm{C}\right)$ for $4 \mathrm{~h}$ increases water loss by $64 \%$ compared to that of birds housed at $24^{\circ} \mathrm{C}$. Water loss was mainly due to an increase in urine production and free water clearing independent of water consumption. Also, an increment of total urinary excretion of $\mathrm{K}^{-}, \mathrm{P}^{-}, \mathrm{Na}^{+}, \mathrm{Mg}^{++}$and $\mathrm{Ca}^{++}$excretion has been reported in the heat stressed broilers. The excretion rout for this effect has been suggested to vary with the specific mineral and heat stress severity (Belay et al. 1992).

The hematological data indicated decreased number of circulating RBCs, Hb concentration and Hct $\%$ due to chronic exposure to heat stress. This may be due to the impact of chronic stress on iron $(\mathrm{Fe})$ in broilers and the hematopoietic process (Jamadar and Jalnapurkar, 1995). Hemoglobin concentration was reduced in all experimental chicks after exposure to acute stress at 42nd day of age. This result is in accordance with findings of Yahav et al. (1997). The Hct showed differential pattern, in control chicks there was an increased level after exposure to acute heat stress. On the other hand, there was a decreased in Hct in thermally- conditioned and chronically-stressed chicks. Increased Hct in controls could be attributed to increased water loss due to panting and the birds were not able to adapt. In the case of thermally-conditioned or chronically-stressed birds, there was an adaptation response in the form of hemo-dilution to compensate water loss and an increase in the bird's ability to lose heat to the environment through water loss by evaporation without compromising plasma volume. Most of this evaporative water loss comes from the extra cellular component (Darre and Harrison, 1987).
Heterophils are phagocytic cells designed to defend the organism against infections by bacteria, viruses, or foreign particles, while lymphocytes play an important role in immunity, particularly for the production of antibodies. One of the physiological responses of exposure to stress is the release of glucocorticoids, causing dissolution of lymphocytes leading to lymphopenia. On the other hand there is an increase in hetrophil release by the bone marrow, thus increasing their number in circulation, but their phagocytic and bactericidal activities are usually very low (Swenson and Reece, 1996). Our results indicated that this type of stress response was significantly high (increased $\mathrm{H}: \mathrm{L}$ ratio) in control birds, lowest in chronicallyexposed chicks followed by those thermallyconditioned at an early age. Our findings for control birds are in accordance with those reported by Zulkifli and Siegel (1995); Borgas (1997); McFarlane and Curtis (1989); McFarlane et al. (1989) and Hester et al., (1996). Our data on H: L ratio clearly showed that early age thermal conditioning was beneficial for the birds to withstand adverse effects of acute heat-stress at marketing age.

\section{CONCLUSION}

Acute heat stress at marketing age has a detrimental effect and leads to respiratory alkalosis in chicks raised in thermo-neutral conditions. The symptoms of stress observed following exposure to acute heat were much less in both thermally-conditioned and chronically-stressed chickens. While beneficial effects of early age thermal conditioning have been shown before, our study demonstrated some of the mechanisms involved in this adaptive response to acute heat stress. Further studies are needed to understand other mechanisms involved as well as the beneficial effects of cyclic conditioning of birds at early age.

\section{ACKNOWLEDGEMENT}

The researchers wish to express their sincere appreciation to Ms. May Hamdy Abd- El- Azeem, post graduate student, Department of Animal Hygiene, Faculty of Veterinary Medicine, Suez Canal University for her assistance in conducting this research.

\section{REFERENCES}

Abu-Dieyeh, Z.H.M., 2006. Effect of chronic heat stress and long-term feed restriction on broiler performance. Int. J. Poult. Sci., 5: 185-190. 
Ait-Boulahsen, A., J.D. Garlich and F.W. Edens, 1989. Effect of fasting and acute heat stress on body temperature, blood acid-base and electrolyte status in chickens. Comp. Biochem. Physiol., 94: 683687. DOI: 10.1016/0300-9629(89)90617-8

Altan, O., A. Altan, M. Cabuk and H. Bayraktar, 2000. Effects of heat stress on some blood parameters in broilers. Turk. J. Vet. Anim. Sci., 24: 145-148.

Arjona, A.A., D.M. Denbow and W.D. Weaver Jr., 1988. Effect of heat stress early in life on mortality of broilers exposed to high environmental temperatures just prior to marketing. Poult. Sci., 67: 226-231. DOI: 10.3382/ps.0670226

Austic, R.E. and C.C. Calvert, 1981. Nutritional interrelationships of electrolytes and amino acids. Fed. Proc., 40: 63-67. PMID: 6778715

Basilio, V.D., M. Vilarin, S. Yahav and M. Picard, 2001. Early age thermal conditioning and a dual feeding program for male broilers challenged by heat stress. Poult. Sci., 80: 29-36. PMID: 11214333

Belay, T. and P.G. Teeter, 1993. Broiler water balance and thermo tolerance during thermo neutral and high ambient temperature exposure. Pout. Sci., 72: 116-124.

Belay, T., C.J. Wiemusz and R.G. Teeter, 1992. Mineral balance and urinary and fecal mineral excretion profile of broilers housed in thermoneutral and heat-distressed environments. Pout. Sci., 71: 1043-1047. DOI: 10.3382/ps.0711043

Borgas, S.A., 1997. Supplemetacao de Cloreto de Potassio Bicarbonate de Sodio Para Frangos de corte Durante o Verao. Dissertacao de mestrado, UNESP, Jaboticabal, Brazil.

Borges, S.A., A.V.F.D. Silva, A. Majorka, D.M. Hooge and K.R. Cummings, 2004. Physiological responses of broiler chickens to heat stress and dietary electrolyte balance (sodium plus potassium minus chloride, milliequivalents per kilogram. Poult. Sci., 83: 1551-1558. PMID: 15384907

Borges, S.A., A.V.F.D. Silva, J. Ariki, D.M. Hooge and K.R. Cummings, 2003. Dietary electrolyte balance for broiler chickens exposed to thermoneutral or heat-stress environments. Environ. Poultry Sci., 82: 428-435.

Cangar, A.Z., J.M. Aerts, J. Buyse and D. Berckmans, 2008. Spatial distribution of surface temperatures and beat loss in broiler chickens. Livestock Environment, Iguassu Falls, Brazil.

Cheveille, N.F., 1979. Environmental factors affecting the immune response of birds: A review. Avian Dis., 23: 308-313.

Ching, C.Y. and C.C. Yeh, 1992. Effect of acute heat stress in the blood characteristics of Taiwan country chickens and broilers. J. Chin. Soc. Anim. Sci., 21: 57-66.
Darre, M.J. and P.C. Harrison, 1987. Heart rate, blood pressure, cardiac output and total peripheral resistance of single comb white leghorn hens during an acute exposure to $35^{\circ} \mathrm{C}$ ambient temperature. Poult. Sci., 66: 541-547. DOI: 10.3382/ps.0660541

Deyhim, F., T. Belay and R.G. Teeter, 1990. The effect of heat distress on blood gas, plasma and urine concentration of $\mathrm{Na}, \mathrm{K}, \mathrm{Cl}$ of broiler chicks. Poult. Sci., 69: 42.

Gross, W.B. and H.S. Siegel, 1983. Evaluation of the heterophil/lymphocyte ratio as a measure of stress in chickens. Avian. Dis., 27: 972-978. PMID: 6360120

Hester, P.Y., W.M. Muir, J.V. Craig and J.L. Albright, 1996. Group selection for adaptation to multiplehen cages: Hematology and Adrenal function. Poult. Sci., 75: 1295-1307. PMID: 8933581

Jamadar, S.J. and B.W.V. Jalnapurkar, 1995. Effect of high ambient temperature on iron status of broilers. Indian Vet. J., 72: 577-579.

Macari, M.R., R.L. Furlan and E. Gonzales, 2002. Fisiologia Aviaria Aplicada a Frangos de Corte. 2nd Edn., FUNEP/UNESP, Jaboticabal, Brazil, ISBN: 8587632485, pp: 375.

McFarlane, J.M. and S.E. Curtis, 1989. Multiple concurrent stressors in chicks. 3. Effects on plasma corticosterone and the heterophil:Lymphocyte ratio. Poult. Sci., 68: 522-527. PMID: 2748500

McFarlane, J.M., S.E. Curtis, J. Simon and O.A. Lzguierdo, 1989. Multiple concurrent stressors in chicks. 2. Effects on hematologic, body composition and pathologic traits. Poult. Sci., 68: 510-521. PMID: 2748499

Raup, T.J. and W.G. Bottjr, 1990. Effect of carbonated water on arterial $\mathrm{pH}, \mathrm{PCO}_{2}$ and plasma lactate in heat-stressed broilers. Br. Poult. Sci., 31: 337-384. PMID: 2372712

Smith, M.O. and R.G. Teeter, 1987. Potassium balance of the 5-8 week-old broiler exposed to constant heat or cycling high temperature stress and the effects of supplemental potassium chloride on body weight gain and feed efficiency. Poult. Sci., 66: 487-492.

Swenson, M.J. and W.O. Reece, 1996. Fisiologia DOS Animais Domesticos/Dukes. 11th Edn., Guanabara, Rio de Jaeiro, Brazil, ISBN: 8527703300, pp: 856.

Wideman, R.F., B.C. Ford, J.D. May and B.D. Lott, 1994. Acute heat acclimation and kidney function in broilers. Pout. Sci., 73: 75-88. PMID: 8165172

Yahav, S. and I. Plavnik, 1999. Effect of early-stage thermal conditioning and food restriction on performance and thermotolerance of male broiler chickens. Br. Poult. Sci., 40: 120-126. PMID: 10405047 
Yahav, S. and S. Hurwitz, 1996. Induction of thermotolerance in male broiler chickens by temperature conditioning at an early age. Poult. Sci., 75: 402-406. PMID: 8778736

Yahav, S., A. Straschhnow, I. Plavnik and S. Hurwitz, 1997. Blood system response of chickens to changes in environmental temperature. Poult. Sci., 76: 627-633. PMID: 9106892
Zhou, W.T., M. Fujita, T. Ito and S. Yamamoto, 1997. Effects of early heat exposure on thermoregulatory responses and blood viscosity of broilers prior to marketing. Br. Poult. Sci., 38: 301-306. PMID: 9280359

Zulkifli, I. and P.B. Siegel, 1995. Is there a positive side to stress? World Poult. Sci. J., 51: 63-76. 